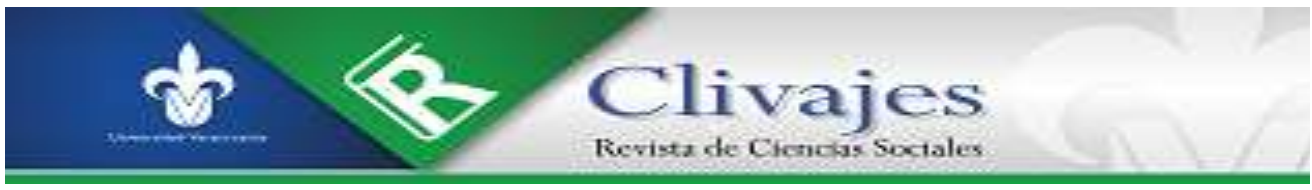

Abel Gómez Gutiérrez

gomez.abel@uan.edu.mx

Universidad Autónoma de Nayarit, México

Isabela Calderón Restrepo

isabela.calderonr@autonoma.edu.co

Universidad Autónoma de Manizales, Colombia

Juan José Montoya Álvarez

juan.montoyaa@autonoma.edu.co

Universidad Autónoma de Manizales, Colombia

GESTIÓN MIGRATORIA EN COLOMBIA Y ÉXODO DE VENEZOLANOS

DESDE UNA MIRADA DEPARTAMENTAL EN EL EJE CAFETERO

(CONTEXTOS MIGRATORIOS EMERGENTES)

DOI: https://doi.org/10.25009/clivajesrcs.i15.2696

Clivajes. Revista de Ciencias Sociales. Año VIII, número 15, enero-junio 2021, pp. 156-190.

https://clivajes.uv.mx/index.php/Clivajes

Instituto de Investigaciones Histórico-Sociales, Universidad Veracruzana

Clivajes. Revista de Ciencias Sociales/ISSN: 2395-9495/IIH-S, UV/Xalapa, Veracruz, México

Recibido: 05/04/2021

Aceptado: 19/04/2021

Dictaminado: 10/05/2021

(c) $($ i) $(9)$

Clivajes. Revista de Ciencias Sociales (ISSN: 2395-9495), Año VIII, Núm. 15, enero-junio, 2021 Instituto de Investigaciones Histórico-Sociales, Universidad Veracruzana, México 


\title{
GESTIÓN MIGRATORIA EN COLOMBIA Y ÉXODO DE VENEZOLANOS DESDE UNA MIRADA DEPARTAMENTAL EN EL EJE CAFETERO (CONTEXTOS MIGRATORIOS EMERGENTES)
}

\author{
Abel Gómez Gutiérrez* \\ Isabela Calderón Restrepo** \\ Juan José Montoya Álvarez ${ }^{* * *}$
}

Resumen

En la última década, la crisis política, social y económica de Venezuela ha provocado un éxodo gradual de venezolanos hacia distintos países de América Latina. La vecindad de Venezuela con Colombia y las múltiples relaciones transfronterizas que unen, y en ocasiones han causado conflictos, a estos dos países se han intensificado en Colombia por la llegada y permanencia de casi dos millones de venezolanos. Al respecto, en este artículo se analiza los cambios en la gestión y política migratoria de Colombia para enfrentar el intenso éxodo de venezolanos y las estrategias del gobierno colombiano para concientizar a su población. Aunque el alcance del éxodo es generalizado en los 32 departamentos de Colombia, se parte de una región específica que incluye los tres departamentos y las ciudades principales del Eje Cafetero: Caldas, Risaralda y Quindío, con el fin de explicar la situación de los migrantes venezolanos, residentes en este territorio. Toda vez que la dinámica del éxodo implica al gobierno y a la sociedad colombiana, se considera la percepción de la población receptora, para cruzar información sobre la gestión migratoria de Colombia en relación con el éxodo venezolano. Independientemente de lo compacto del territorio de la región del Eje Cafetero, por sus antecedentes formativos, se establece que en los tres departamentos existen distintos comportamientos e identidades sociales, y que éstos se manifiestan en las actitudes y en la percepción de apertura de la población colombiana hacia los migrantes venezolanos.

Palabras clave: Gestión migratoria, Éxodo venezolano, Migración y política migratoria

\section{MigRATION MANAGEMENT IN COLOMBIA AND THE EXODUS OF VENEZUELANS FROM A DEPARTMENTAL PERSPECTIVE IN THE COFFEE REGION (EMERGING MIGRATION CONTEXTS)}

Abstract

In the last decade, the political, social and economic crisis in Venezuela has caused a gradual exodus of Venezuelans to different countries in Latin America. The neighborhood of Venezuela with Colombia and the multiple cross-border relations that unite, and which sometimes have caused conflicts to both countries, have been intensified in Colombia due to the arrival and permanence of almost two million Venezuelans. In this regard, this article analyzes the changes in the management and migration policy of Colombia to face the intense exodus of Venezuelans and the strategies of the Colombian government to raise awareness among its population. Although the scope of the exodus is generalized in the 32 departments of Colombia, it starts from a specific region that includes the three departments and the main cities of the Coffee Growing Axis: Caldas, Risaralda and Quindío, in order to explain the situation of Venezuelan migrants, residents in

${ }^{*}$ Docente-investigador en la Unidad Académica de Ciencias Sociales de la Universidad Autónoma de Nayarit, México, y coordinador del Cuerpo Académico UAN318 sobre Política social y Migraciones; es miembro del Sistema Nacional de Investigadores, Nivel 1 y Perfil PRODEP; doctor en Ciencias Sociales, con especialidad en Relaciones de Poder y Cultura Política, por la Universidad Autónoma MetropolitanaXochimilco (UAM-X). Línea de investigación: Migración internacional y relaciones transnacionales de poder de las organizaciones de mexicanos en Estados Unidos.

** Politóloga con énfasis en Gobierno y Relaciones Internacionales de la Facultad de Estudios Sociales y Empresariales en la Universidad Autónoma de Manizales, Colombia. Becaria del Programa de Intercambio Latinoamericano (PILA, 2018-2).

*** Politólogo con énfasis en Gobierno y Relaciones Internacionales de la Facultad de Estudios Sociales y Empresariales en la Universidad Autónoma de Manizales, Colombia, e investigador en el campo del Derecho Internacional Humanitario (DIH), el Derecho Internacional de los Derechos Humanos (DDHH) y las migraciones. 
this territory. Since the dynamics of the exodus involves the government and Colombian society, the perception of the receiving population is considered to cross-check information on Colombia's migration management in relation to the Venezuelan exodus. Regardless of the compactness of the territory of the Coffee Axis region, due to its educational background, it is established that in the three departments there are different behaviors and social identities, and that these are manifested in the attitudes and perception of openness of the Colombian population towards Venezuelan migrants.

Keywords: Migration management, Venezuelan exodus, Migration and migration policy

\section{GESTION MIGRATOIRE EN COLOMBIE ET EXODE DE VENEZUELIENS A PARTIR D'UN REGARD DEPARTEMENTAL DANS L'AXE CAFETIER (CONTEXTES MIGRATOIRES EMERGENTS)}

\section{Résumé}

Dans la dernière décennie, la crise politique, sociale et économique du Venezuela a provoqué un exode progressif de vénézuéliens vers divers pays d'Amérique Latine. La proximité du Venezuela avec la Colombie et les multiples réactions transfrontalières qui unifient ces deux pays et qui parfois ont provoqué des conflits, se sont intensifiées en Colombie à cause de l'arrivée de presque deux millions de vénézuéliens et leur permanence en ce pays voisin. À cet égard, dans cet article on analyse les changements dans la gestion et la politique migratoire de la Colombie pour faire face à l'intense exode de vénézuéliens et les stratégies du gouvernement colombien pour sensibiliser leur population. Même si la portée de l'exode est généralisée dans les 32 départements de la Colombie, on part d'une région spécifique qui inclue les trois départements et les villes principales de l'Axe Cafetier : Caldas, Risaralda et Quindío, afin d'expliquer la situation des migrants vénézuéliens, résidents dans ce territoire. Toutefois que la dynamique de l'exode implique au gouvernement et à la société colombienne, on considère la perception de la population destinataire pour échanger de l'information sur la gestion migratoire de la Colombie en relation avec l'exode vénézuélien. Nonobstant le compact du territoire de la région de l'Axe Cafetier à cause de ses antécédents formatifs, nous établissons que dans les trois départements il y a des différents comportements et identités sociales et qu'ils se manifestent dans les attitudes et dans la perception d'ouverture de la population colombienne envers les migrants vénézuéliens.

Mots Clés : Gestion migratoire, Exode vénézuélien, Migration et politique migratoire

\section{INTRODUCCIÓN}

"Hacemos pública la decisión de nuestro país de crear un estatuto de protección temporal en Colombia que nos permita hacer un proceso de regularización de los migrantes (venezolanos)”, dijo el mandatario, [Iván Duque] acompañado por el alto comisionado de las Naciones Unidas para los refugiados, Filippo Grandi.

(BBC Mundo, 9 de febrero 2021).

El anuncio hecho por el Presidente Iván Duque sobre regularización migratoria en Colombia es el más ambicioso que se haya considerado entre los países de América Latina, incluso supera los mecanismos implementados por Perú y Argentina en relación con los migrantes venezolanos que forman parte del éxodo gradual de los últimos diez años y que se intensificó de 2016 a 2019. El éxodo venezolano de la década más reciente hacia todos los países de América Latina constituye parte de los contextos migratorios emergentes en el mundo; por lo tanto, el objetivo principal de este artículo es analizar el proceso migratorio acumulado en Colombia desde tres departamentos que componen el Eje Cafetero y las acciones del gobierno, en conjunto con organismos 
internacionales y las autoridades departamentales, para hacer frente a dos aspectos fundamentales: la llegada, tránsito y permanencia de casi dos millones de migrantes venezolanos, y concientizar a la sociedad colombiana receptora para conocer e implementar las nuevas resoluciones y decretos gubernamentales, evitar el acoso, disminuir la xenofobia, respetar los derechos sociales y humanos de los migrantes venezolanos e impedir actos de corrupción.

Si bien nuestra localización física y de contacto con migrantes venezolanos y sociedad colombiana se realizó en las ciudades de Manizales (Departamento de Caldas) y Pereira (Departamento de Risaralda) durante los meses de agosto a octubre de 2019. este documento incluye un marco teórico conceptual y metodológico basado en la teoría de interdependencia compleja para tratar de explicar el fenómeno Venezuela y su impacto global en las relaciones internacionales, y su contraparte Colombia, que atrae los reflectores mediáticos y las miradas de sus vecinos, por este protagonismo internacional en las formas que está utilizando el éxodo venezolano para actualizar sus políticas migratorias y alcanzar los beneficios que ofrecen los organismos internacionales y el gobierno de los Estados Unidos de América (EE.UU.).

Las relaciones binacionales intensas y extensas entre dos países con una amplia frontera de por medio, como Venezuela y Colombia, podrían conceptualizarse desde distintos enfoques, ya que han existido fluctuaciones entre sus fuentes de poder — de ambos países — en los 30 años más recientes. Sin embargo, a finales de la década de 1970, Robert Keohane y Joseph Nye (1977) ya vislumbraban los cambios en la prioridad temática de las agendas, la apertura de múltiples canales de comunicación, la participación de otros actores internacionales y a las migraciones como un factor de transformación en las relaciones internacionales. Por lo tanto, se abre un abanico conceptual en relación con las migraciones y la forma en que tanto Venezuela como principalmente Colombia están gestionando el éxodo venezolano.

Se priorizan los conceptos de migración, gestión de la migración y gestión de las fronteras por parte de las agencias internacionales, como la Organización Internacional de las Migraciones (OIM), y del gobierno colombiano.

El éxodo venezolano hacia América Latina, y en particular hacia Colombia, goza de atención mediática y ya se identifican algunas publicaciones en organismos internacionales como la Cruz Roja y revistas especializadas. Sin embargo, nuestra geolocalización en el Eje Cafetero de Colombia nos permite una mirada distinta, ya que las fuentes de información son escasas. La publicación más cercana a nuestro artículo es la 
de la Cruz Roja de Colombia, en la cual se incluyen dos departamentos fronterizos: Cúcuta y Soacha (2019). Para agosto de 2019, los migrantes venezolanos, apenas comenzaban a llamar la atención de los medios de comunicación y la academia dentro de las universidades de la ciudad de Manizales y Pereira. Por lo tanto, se revisó la metodología de las dimensiones migratorias en las entidades federativas de México en compañía de estudiantes y docentes-investigadores de la UAM.

Se utilizó un tipo de investigación exploratoria-explicativa, con enfoque cualitativo basado en la revisión bibliográfica institucional y mediática, temporalizada sobre el proceso migratorio de lo que se conoce como el éxodo venezolano hacia los países de América Latina y el Caribe. Es exploratoria, porque los departamentos del Eje Cafetero de Colombia son los que menos migrantes venezolanos habían recibido hasta el mes de septiembre 2019, y esta región es donde sus académicos investigadores habían puesto menor atención a ese proceso migratorio; de ahí que sólo se encontraran datos estadísticos aproximados, publicados por las agencias dependientes de Migración Colombia, y se comenzara a identificar a los migrantes venezolanos que estaban de paso (tránsito) y los que ya habían seleccionado esta región para establecerse temporalmente. Fue en este contexto que se diseñó un instrumento de preguntas básicas, para romper el hielo, ganar confianza y ampliar el listado de posibles migrantes venezolanos ya establecidos en Manizales para realizar las entrevistas.

En la segunda parte de este trabajo se incluye un breve análisis del proceso y de los cambios adoptados por el gobierno de Colombia denominado como -un antes y un después- de la intensa llegada de venezolanos a Colombia. Además, se da cuenta de las entrevistas estructuradas realizadas a migrantes venezolanos y miembros de la sociedad colombiana de ambas ciudades mencionadas. El objetivo principal de las entrevistas gira en dos vertientes: primero, explorar el entendimiento de una sociedad receptora de migrantes venezolanos fuera del radar universitario en la ciudad de Manizales; segundo, explorar las expresiones y actitudes de los migrantes venezolanos, en su mayoría indocumentados/irregulares, o con el permiso temporal de estancia vigente o vencido.

Las entrevistas estuvieron enfocadas a identificar la postura de la población receptora en relación con su conocimiento de los procesos migratorios de Colombia, las causas del éxodo venezolano, la influencia de los medios de comunicación, la gestión migratoria de Colombia y su opinión de las acciones gubernamentales federales y locales para administrar los flujos migratorios. Las entrevistas a los venezolanos residentes en Manizales y Pereira estuvieron orientadas a identificar: las causas de la 
migración, selección de estas ciudades, escolaridad, actividades económicas, gestión migratoria colombiana y actitudes de la sociedad receptora.

Se incluye un apartado con el cruce de información relacionado con la toma de decisiones institucionales a nivel federal y la percepción mediática sobre la carencia de estrategias informativas sub-nacionales en relación con los intensos procesos migratorios por territorio colombiano.

\section{TEORÍA/CONCEPTOS: INTERDEPENDENCIA COMPLEJA Y GESTIÓN DE LA MIGRACIÓN}

Los procesos migratorios internacionales están transformando las agendas fundamentales del orden mundial. Estos procesos son de larga data y se remontan a los primeros periodos de la historia de la humanidad; sin embargo, sería anacrónico y casi necio comparar el fenómeno en tiempos pasados y como es en la actualidad, debido a la complejidad, tamaño y desarrollo de la población migrante internacional. Desde finales del siglo xx, Castles y Miller (2004) afirmaban, en su libro la Era de las Migraciones: "los movimientos migratorios intensos, extensos y variados". Al tiempo, en los últimos años la migración ha surgido como un desafío político y normativo fundamental en cuestiones tales como los desplazamientos, la gestión de las fronteras, la migración segura y la integración en distintas regiones del mundo (ACNUR, 2012).

La migración, como fenómeno social, trae consigo efectos y consecuencias no sólo para los países receptores, sino también para los migrantes y los países de origen. Cuando el fenómeno se evidencia de manera masiva debido a problemas económicos, políticos y sociales en un Estado determinado, el orden nacional y las relaciones regionales pueden verse alteradas. De acuerdo con la OIM (2021): "se calcula que, en 2020 había 279 millones de migrantes internacionales en todo el mundo (3,3\% de la población mundial); lo que representa un incremento respecto de los 155 millones de migrantes estimados en el año 2000 (2,8\% de la población mundial)”. La migración interna es incluso más prevalente: las estimaciones mundiales más recientes indican que más de 1000 millones de personas han migrado dentro de su propio país de nacimiento. Esto demuestra la tendencia hacia la movilidad que poseen las personas bajo circunstancias que determinan las condiciones de vida, como aspectos socioeconómicos, políticos, familiares, religiosos y medioambientales (OIM , 2018, pág. 15). 
La interdependencia mundial [compleja] implica efectos costosos de transacciones y que los actores se vean afectados por las acciones de otros. Asimismo, la interdependencia no tiene que ser asimétrica, ya que las asimetrías son las que más probablemente influyan en las relaciones de los actores (Keohane, 2013, p.120). Además, reitera Keohane, el poder juega un papel preponderante en las relaciones interdependientes y asimétricas. Los Estados-nación de Venezuela y Colombia podrían catalogarse dentro del rango simétrico de poder, ya que cuentan con una historia de conquista y un proceso indistinto de independencia, así como su nacimiento como Estados en 1810. Sus diferencias entre extensión territorial y población son mínimas. Ambos países cuentan con población indígena y afrodescendiente. Sin embargo, hace ya 22 años que Venezuela se ha apartado de los designios del Consenso de Washington, el Banco Interamericano de Desarrollo (BID) y el Fondo Monetario Internacional (FMI), y mantiene en la práctica un distanciamiento con todo lo que tenga que ver con el Imperio norteamericano y algunos organismos internacionales. Asimismo, ha fortalecido su ejército y aumentado el presupuesto para defensa, de acuerdo con algunas fuentes, hasta los 4000 millones de dólares (Tokatlian et al., 2019). En respuesta, EE.Uu., el Secretario General de la Organización de los Estados Americanos (OEA), algunos organismos regionales y otros 60 países se han manifestado en contra de las políticas económicas, los procesos político-electorales "cuestionables", los problemas sociales y la intensa persecución y violencia política en contra de los opositores al régimen. Incluso se manifestaron públicamente a favor de Juan Guaidó para ocupar la presidencia de la República Bolivariana de Venezuela. Colombia, por su parte, ha fortalecido sus relaciones con EE.UU. todo lo que Venezuela y otros países, como Bolivia, Cuba y Nicaragua, se han alejado en estos mismos 22 años; Cuba ya cumplió 62 años de distanciamiento y embargos.

El planteamiento teórico de la Interdependencia Compleja está relacionado con la intensidad global que tanto Venezuela como Colombia mantienen permanentemente, desde la forma encontrada de su política interna, hasta las relaciones internacionales y las formas que han hallado para buscar alianzas con las potencias del mundo. No es menor mencionar el intervencionismo (la cooperación) de EE.uU., Rusia, China, India e Irán en estos dos países, sin ignorar la Unión Europea, dividida entre los intereses que resguarda en Venezuela y los que ha creado recientemente en Colombia. Otros factores que influyen en la complicada vecindad de estos países son los organismos regionales, la Organización de los Estados Americanos (OEA), las organizaciones internacionales del Trabajo (OIT), de la Salud (OMS), de las 
Migraciones (OIM) y del Alto Comisionado de la ONU para los Refugiados (ACNUR). Sin dejar de mencionar la Organización Mundial del Comercio (OMC). Estos dos países han sido noticia permanente en los principales medios de comunicación del mundo y lo principal es que sus aliados y la ONU conocen los altos costos de intervención en Venezuela, muy a pesar de la política interna e internacional de este país.

La importancia que han cobrado los actores no estatales, la multiplicación de las relaciones y canales transnacionales, las corrientes migratorias, la integración regional en Europa y en América del Norte, y la integración de China al Sistema capitalista internacional son fenómenos de la globalización contemporánea que confirman la validez y el carácter visionario de la Teoría de la Interdependencia formulada por el profesor Robert Keohane (Borja, 2020, p. 208). Para efectos de este artículo, se prioriza el tema de las migraciones internacionales, en particular la intensidad del inesperado y masivo éxodo venezolano por toda América Latina en los tres años de observación 2016-2019. En relación con el éxodo venezolano y la gestión migratoria del gobierno colombiano, es necesaria la inclusión conceptual de la gestión migratoria, ya que el documento gira por esta pendiente que incluye la gestión de la extensa frontera con Venezuela. Posteriormente se establecerán los tipos de migración que experimenta Colombia de acuerdo con su legislación y gestión migratoria.

\section{LA GESTIÓN MIGRATORIA DEL ESTADO COLOMBIANO}

La página oficial de la OIM contiene un glosario-guía para evitar confusiones a quienes consultan, se capacitan o desean ampliar su bagaje de conocimientos conceptuales sobre las migraciones. Por lo tanto, la gestión migratoria se define como:

Gestión de la migración - Gestión y ejecución, principalmente por los Estados en el marco de los sistemas nacionales o a través de la cooperación bilateral y multilateral, de un conjunto de actividades que abarca todos los aspectos de la migración y la incorporación de las consideraciones relativas a la migración en las políticas públicas. Este término remite a los enfoques planificados para la aplicación y puesta en práctica de los marcos normativos, legislativos y administrativos elaborados por las instituciones encargadas de la migración (OIM-glosario).

La idea y el concepto de gestión toman fuerza en Estados Unidos e Inglaterra hacia finales de la década de 1970 y se fortalece a lo largo de la década de 1980. Ésta pronto sería adoptada por la Organización para la Cooperación y el Desarrollo 
Económicos (OCDE) y sus miembros. En cada uno de los reportes anuales de la OCDE sería sugerida, "recomendada" y diseminada como receta para los países del resto del mundo gracias a los programas de los organismos internacionales (BM, FMI, BID, OIM, ONU) (Estupiñán, 2013). De acuerdo con la autora y crítica de los organismos regionales e internacionales, Estupiñán Serrano:

Esto ocurre porque una vez que los economistas de la Escuela de Friburgo (Alemania) y la Escuela de Chicago (Estados Unidos) establecen el programa neoliberal, requieren el apoyo de sus colegas de las áreas de administración y negocios (y poco después del área de Relaciones Internacionales) para materializar el nuevo rol del Estado, cuya otrora centralidad debía ser cedida al mercado. Éstos ponen entonces en el centro la técnica de la gestión en aras del "buen gobierno" (Estupiñán, 2013, p. 6).

En dichas áreas ya se venían realizando ajustes y propuestas para aplicar al sector público prácticas empresariales que permitieran reducir el protagonismo del Estado, maximizar beneficios, flexibilizar estructuras y dar vía libre a la competencia; criterios que, por lo demás, son un claro correlato con el programa de los economistas de Friburgo y de Chicago. De esta manera surge la Nueva Gestión Pública (NGP, New Public Management -NPM), que pese a la imprecisión en su definición (estrategia por lo demás común y no gratuita en la formulación de terminología neoliberal) y a la diversidad de técnicas que emplea. La NGP es una tecnología de poder que tiene una meta clara: "modificar la administración pública de tal manera que aún no sea una empresa, pero que se vuelva más empresarial (Estupiñán, 2016, p.8).

En la misma década de los noventa, esta línea de pensamiento fue desbordándose del marco empresarial e introduciéndose en las ciencias sociales, ya no utilizando el conocimiento de estas áreas para ejecutar sus programas, sino a través de la lógica de la gestión instalada en el centro a partir del cual se generan conocimientos. No puede librarse de la responsabilidad de prestar servicios eficientes y efectivos dentro de la economía; sin embargo, tampoco mostrará una orientación hacia la generación de utilidades, como es la obligación indispensable de una empresa que quiere mantenerse competitiva dentro del mercado" (Schröder, s.f., p. 8, cit. en Estupiñán, 2013). Los organismos internacionales, como la OCDE y la OMC, y agencias internacionales, como la OIM, también promueven la aplicación de este modelo. Es más, sus programas están diseñados para optimizar la gestión de los recursos, ora humanos, ora materiales, como lo veremos más adelante en el caso de la OIM (Estupiñán, 2013, pp. 8-10). 
Estas afirmaciones están basadas en un seguimiento puntual de los documentos, convenciones y discurso de los representantes de estos organismos, y además no son letra muerta u oculta. La página principal de la OIM muestra de manera explícita la importancia de uno de sus departamentos, el de "gestión":

El Departamento de Gestión de la Migración [de la OIM] se encarga de definir la orientación política para las Oficinas exteriores; de formular las estrategias globales; de establecer las normas y el control de calidad; de gestionar el conocimiento con relación a la incorporación de los sectores de la migración, incluida la migración laboral y facilitada, la migración y el desarrollo, la lucha contra la trata de personas, el retorno voluntario asistido, la migración y salud, la asistencia a migrantes vulnerables, la inmigración y gestión de fronteras, y el fortalecimiento institucional global en materia de gestión migratoria. Adicionalmente, se encarga del manejo del Fondo de la OIM para el Desarrollo. Este Departamento tiene a su cargo la evaluación, aprobación y gestión de proyectos multirregionales y mundiales. Igualmente, se encarga de la supervisión técnica de expertos en las Oficinas exteriores, en materia de evaluación y aprobación de proyectos. También se ocupa de las relaciones operacionales con asociados pertinentes gubernamentales, multilaterales y del sector privado e industrial, y ello en coordinación con el Departamento de Cooperación Internacional y Partenariados.

El Departamento de Gestión de la Migración se compone de cuatro divisiones y una unidad:

a) División de Migración y Salud;

b) División de Gestión de Inmigración y Fronteras;

c) División de Asistencia a los Migrantes;

d) División de Migración Laboral y Desarrollo Humano; y

e) Unidad del Fondo de la OIM para el Desarrollo (OIM Portal principal).

En nuestra propia experiencia, en las oficinas de las sedes de la OIM en México como en Colombia, sus representantes son extremadamente cuidadosos con las formas. Cada sede depende de la formulación de proyectos con presupuestos que incluyen la contratación de personal, es decir, los mismos proyectistas se incluyen como operadores de los programas (Lo que visualizamos es que se encuentran entre la espada y la pared, y no se pueden disparar a sus propios pies). Los presupuestos de los programas que se desarrollan en cada país son financiados por algunas empresas transnacionales y por la Hacienda del país sede; comprendemos, por tanto, la crítica e impotencia expresadas por Estupiñán Serrano (2013). 
La gestión migratoria y la gestión de fronteras están intrínsecamente vinculadas; sin embargo, existen líneas muy delgadas que las diferencian, ya que en las fronteras se administran los flujos de personas, automóviles, mercancías, turistas extranjeros, salida e ingreso de nacionales, de modo que la misma OIM define la gestión de fronteras como:

Gestión de fronteras-Administración de las medidas relacionadas con el movimiento autorizado de personas (migración regular) y bienes, al tiempo que se previene el movimiento no autorizado de personas (migración irregular) y bienes; se detecta a los responsables del tráfico, la trata de personas y los delitos conexos; y se identifica a las víctimas de tales delitos o a cualquier otra persona que requiera asistencia inmediata o a más largo plazo y protección (internacional).

Los supuestos de push and pull que dominaron las migraciones del siglo XIX y XX, analizados y expuestos por Ravenstein desde 1889, y la generalización de la teoría neoclásica de los mercados globales, que dominaron los estudios desde una perspectiva lineal Sur-Norte de las migraciones laborales, presentan retos para la comprensión de los nuevos fenómenos migratorios SUR-SUR que estamos experimentado en el primer cuarto del siglo XXI. El éxodo venezolano ha sido un proceso constante en la década más reciente; sin embargo, se intensificó durante el año 2016 y se desbordó después de las elecciones presidenciales de 2019.

En el contexto del éxodo venezolano hacia Colombia, podemos evidenciar algunos de los supuestos generales de la interdependencia compleja en una relación binacional. En primer lugar, los canales múltiples que se pueden evidenciar en la relación Colombia-Venezuela demuestran que los Estados, en este caso el colombiano y el venezolano, no son los únicos agentes que se encuentran en una relación de intercambio o de dependencia, como la historia lo ha destacado en la relación limítrofe. En segundo lugar, la falta de jerarquización entre las cuestiones se puede evidenciar en tanto las dinámicas políticas del Estado colombiano frente al venezolano han variado. Unos años atrás, durante la presidencia de Álvaro Uribe Vélez los colombianos mostraron cómo la política exterior de Uribe se orientó única y exclusivamente a responder al hostigamiento del gobierno venezolano de Hugo Chávez (Hector Galeano David, et.al, 2019, pág. 65).

En relación con lo anterior, el papel de las fuerzas militares ha sido destacable en algunos Estados, los cuales han brindado una perspectiva mucho más completa a los temas de seguridad y no se limitan únicamente a los temas militares. En el caso 
Venezuela-Colombia se puede evidenciar cómo las políticas que lidera el gobierno colombiano han dejado de ser sólo interés o prioridad para las fuerzas militares. La relación inter-estatal se ha convertido en un tema multidimensional en donde varios entes del gobierno colombiano han dado prioridad a asuntos como la seguridad nacional y territorial, y en especial al tema migratorio: salud de los venezolanos en Colombia, nacionalidad a hijos de padres venezolanos en el país, empleo y seguridad de migrantes venezolanos en el territorio colombiano, para lo que el gobierno está implementando medidas tales como otorgar la permanencia a casi dos millones de venezolanos y regularizar a casi un millón que se encuentra fuera del alcance de las autoridades colombianas o con permiso vencido (Sánchez, 2021, pp. 1-2).

Aun así, desconocer el papel militar al interior de las esferas internacionales es inadecuado, pues, para los países que se aproximan a la interdependencia compleja, en este caso una interdependencia simétrica, persisten dos serias salvedades: 1) un drástico cambio social o político puede determinar que la fuerza vuelva a ser un instrumento importante de la política; y 2) aun cuando los intereses de las élites sean complementarios, un país que emplea la fuerza militar para proteger a otro puede tener significativa influencia política sobre éste (Keohane y Nye, 2008).

En cuanto a lo conceptual, existen similitudes en la observación de las distintas dimensiones migratorias que se ubican en los departamentos colombianos: migración de origen, de destino, de retorno, de tránsito y pendulares. En el caso de este documento, nos referimos a las definiciones asumidas por el gobierno de Colombia para tratar de operacionalizar los distintos significados que se utilizan en la gestión migratoria. Estas son las formas en que Colombia ha tipificado seis tipos de migración:

1. El primero es conocido como la migración de retorno, es decir, los colombianos que se fueron hace unas décadas y regresan debido a la mejora en las condiciones del país.

2. El segundo tipo es la migración de tránsito, que ha generado gran impacto porque se trata de extranjeros que llegan a Colombia de paso, ya sea porque van hacia Norteamérica o desde Venezuela al sur del continente.

3. Una tercera migración es la de destino; es decir, los extranjeros que ven a Colombia como una opción de vida y quieren quedarse.

4. La migración de origen es la cuarta tipología, y son colombianos que se fueron al exterior, pero regresaron tras registrar problemas de comportamiento.

5. La quinta es una migración nueva y es la temporal. En este caso, no se trata de extranjeros que tengan a Colombia como tránsito o como destino, sino que 
permanecen en las fronteras por temas de necesidad, ya sea de conseguir alimentos o de trabajar (Zuñiga, 2017).

6. El concepto de tránsitos pendulares está identificado con la emisión de Tarjetas de Movilidad Fronteriza (TMF) entre Venezuela y Colombia para efectos de comercio y turismo intenso que se manifiesta en los departamentos fronterizos.

Existe una observación puntual en la migración de origen, ya que, para los estudios migratorios de México, por ejemplo, la migración de origen implica a los migrantes que se van de México y se establecen en otros países, que se denominan países destino. En todo caso, la migración de retorno en México incluye a todos los migrantes sin distinguir el tipo de comportamiento por el cual están de retorno.

En términos prácticos, la migración de tránsito, como afirma Chistian Krüger del Ministerio de Relaciones Internacionales, alude más bien a que "un gran porcentaje de los ciudadanos venezolanos que ingresaban a Colombia están utilizando a nuestro país como puente hacía terceros destinos". Esta dinámica no sólo se ha mantenido, sino que, incluso, se ha acrecentado en los últimos meses, siendo los principales destinos Ecuador, Estados Unidos, Panamá, Perú y Chile (Zuñiga, 2017). Sin embargo, como se ha visto anteriormente en las cifras, otra gran cantidad de venezolanos se establecen en Colombia; en consecuencia, tendríamos que estar refiriéndonos a una dimensión migratoria de destino.

\section{ÉXODO DE VENEZOLANOS EN AMÉRICA LATINA}

A partir de un comunicado de prensa de la Comisión Interamericana de Derechos Humanos (CIDH, 2017): "un gran número de venezolanos se ha visto forzado a emigrar a otros países de la región como mecanismo de supervivencia, como consecuencia de la situación humanitaria, en particular por los efectos que vienen ocasionando la escasez de alimentos, medicamentos y tratamientos médicos”. De igual forma, Luis Almagro, Secretario General de la OEA, expresó que "la ciudadanía en Venezuela está sufriendo una violación sistemática de sus derechos humanos por la crisis, lo cual los incentiva a tomar un rumbo hacia las fronteras, para escapar de tal realidad" (Contreras, 2017).

Los factores que influyen en cada migrante en su decisión de cruzar la frontera son, entre otros, laborales, familiares, de educación, problemas de salud. Entre Venezuela y Colombia, existe una gran migración que es de tipo pendular, es decir, muchos de los migrantes venezolanos cruzan la frontera, pero el mismo día retornan a su 
país de origen. Este tipo de ingreso diario y constante es incentivado por la necesidad de la compra de víveres y medicamentos, pues los servicios de salud y la seguridad alimentaria son derechos a los cuales los venezolanos no pueden acceder actualmente en su país. Por tal motivo, las personas cruzan la frontera para comprar lo necesario, pero al no tener los suficientes ingresos para arrendar o establecerse en Cúcuta, retornan a su país (Contreras, 2017).

Medios de comunicación como la BBC, El País, y otros han dado seguimiento puntual a la intensa movilidad de los migrantes venezolanos: "El éxodo de los venezolanos es el mayor de Latinoamérica en los últimos 50 años”. La fuente informó que en un solo día se registró un número nunca antes visto de migrantes pasando la frontera entre Venezuela y Colombia. "La Organización de las Naciones Unidas (ONU) tiene un registro de 2.3 millones de refugiados venezolanos que abandonaron el país durante los años 2016-2018, lo que indica que la cifra ha sido creciente" (BBC, 2019). Este artículo es incisivo referente a la percepción de sus editores: "Huyen de la peor crisis económica de la historia reciente del país, con la mayor inflación del mundo y con problemas de desabastecimiento de alimentos, medicinas y productos básicos” (BBC, 2019).

La misma $\mathrm{BBC}$ ha recurrido al experto en temas de América Latina, Eric L. Olson, director adjunto del Programa de América Latina del Centro de estudios Wilson, con sede en Washington para fortalecer el artículo. Erick L. Olson ha llegado a describir lo que está pasando en Venezuela, "como la mayor ola migratoria que ha vivido la convulsa región en los últimos cincuenta años". Olson aseguró que "aunque en Centro América hay problemas de carácter interno como en el caso de Nicaragua el éxodo venezolano es sin duda alguna el problema de mayor dimensión en la región pues involucra al mayor número de países: Colombia, Perú, Ecuador, Chile, Brasil, incluso pequeños países del Caribe y en Centroamérica” (BBC, 2019). 


\section{Figura 1. ${ }^{1}$}

\section{Principales destinos de la ola migratoria venezolana, 2016-2019}

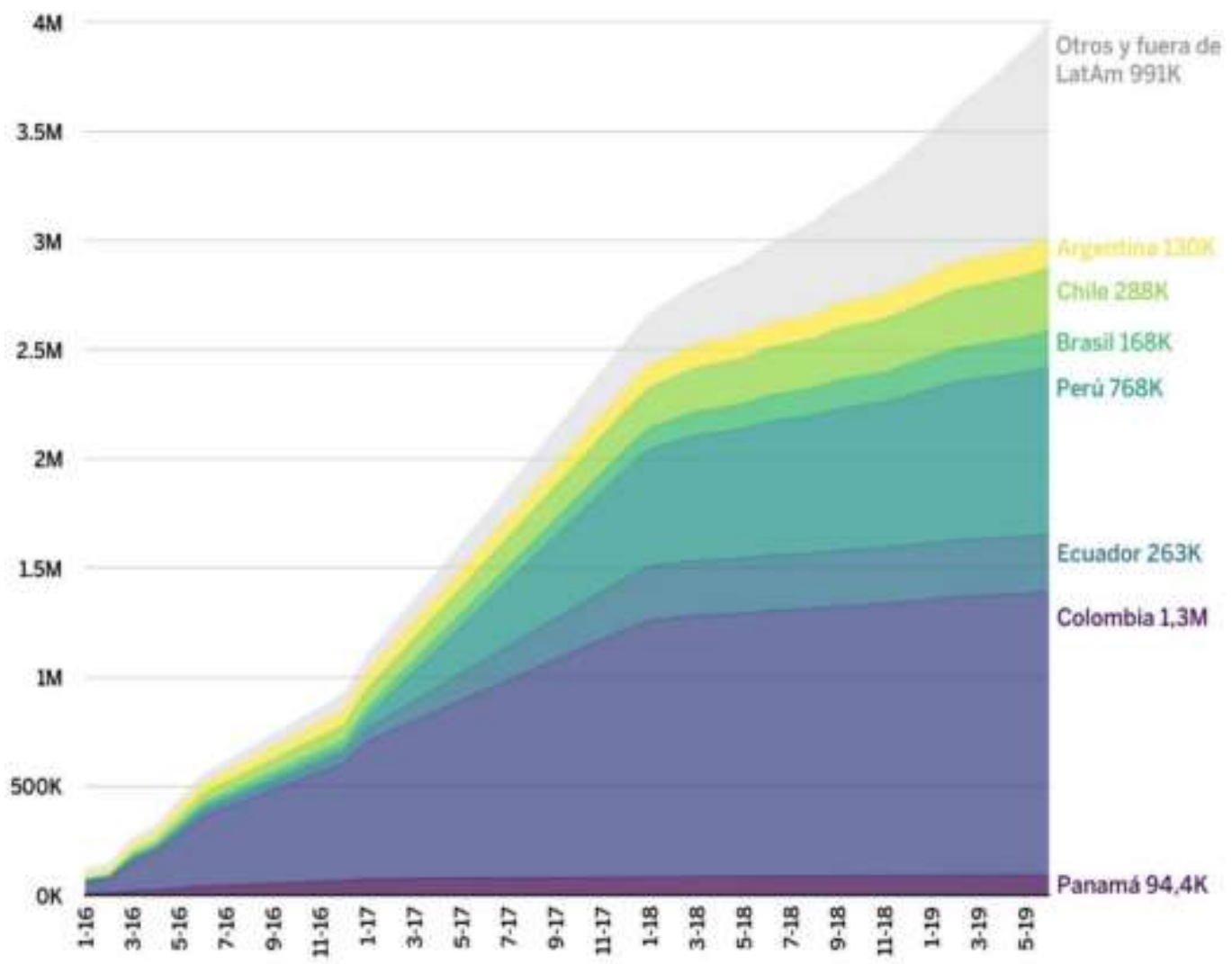

Fuente: Elaboración propia con datos de ONU-ACNUR y OIM

La situación de desabastecimiento de alimentos y productos personales, la constante devaluación de su moneda y el aumento de precios en Venezuela son las principales causas de los desplazamientos. Los puntos de control fronterizo colombianos se vieron rebasados por las multitudes y los migrantes venezolanos se internaron caminando por carreteras, caminos y brechas de Colombia. Durante nuestro periodo de observación en las carreteras del Eje Cafetero — principalmente de Antioquía a Pereira_, durante los meses de agosto y septiembre de 2019 logramos ver a cientos de grupos familiares venezolanos caminando; otros, acampando en lotes baldíos de las ciudades y pueblos; otros más, solicitando apoyo económico y alimentos a los conductores de autos.

\footnotetext{
${ }^{1}$ Tomado de estimaciones realizadas por la plataforma de Coordinación para Refugiados y Migrantes de Venezuela integrada por ACNUR y IOM. 
Según la Comisión Económica para América Latina (CEPAL), la coyuntura migratoria entre Colombia y Venezuela ha estado permeada por las situaciones internas de ambos países, que en determinado tiempo establecieron el número de personas migrantes por la zona de frontera (Contreras, 2017). Sin embargo, el flujo de migrantes provenientes de Venezuela hacia Colombia se incrementó a partir de 2016. En 2017, La OIM y el gobierno colombiano calcularon en 600000 el número de venezolanos en Colombia; una cantidad aproximada que no incluye a solicitantes de asilo, ni puede más que estimar el número de migrantes irregulares que desborda toda capacidad de caracterización oficial. Porcentualmente, el 66\% de los venezolanos que llegaron legalmente a Colombia en 2017 se quedaron, la mayoría de ellos ingresó por vía terrestre, por los pasos fronterizos de La Guajira, Norte de Santander, Arauca y el Vichada (Ordóñez \& Ramírez Arcos, 2019), por lo que se puede establecer que las cifras no son exactas.

\section{GESTIÓN MIGRATORIA DE COLOMBIA, ANTES/DESPUÉS}

El Sistema Integrado de Gestión de la Unidad Administrativa Especial de Migración Colombia es una herramienta de gestión sistemática y transparente compuesta por el conjunto de orientaciones, procesos, políticas, metodologías, instancias e instrumentos que permiten el ejercicio articulado y armónico para dirigir y evaluar el desempeño de la entidad, en términos de calidad y satisfacción social, en la prestación de los servicios, considerando los diferentes modelos referenciales que aplican en (Migración Colombia) MRE.

De acuerdo con la Constitución de Colombia de 1991, el artículo 13, a la letra menciona:

Todas las personas nacen libres e iguales ante la ley, recibirán la misma protección y trato de las autoridades y gozarán de los mismos derechos, libertades y oportunidades sin ninguna discriminación por razones de sexo, raza, origen nacional o familiar, lengua, religión, opinión política o filosófica. El Estado promoverá las condiciones para que la igualdad sea real y efectiva y adoptará medidas en favor de grupos discriminados o marginados. El Estado protegerá especialmente a aquellas personas que, por su condición económica, física o mental, se encuentren en circunstancia de debilidad manifiesta y sancionará los abusos o maltratos que contra ellas se cometan (Articulo 13., 1991, pág. Constitución Política).

Clivajes. Revista de Ciencias Sociales (ISSN: 2395-9495), Año VIII, Núm. 15, enero-junio, 2021 Instituto de Investigaciones Histórico-Sociales, Universidad Veracruzana, México 
Colombia ha transitado por ocho constituciones desde el periodo de independencia en 1808 a 1896. La Constitución de 1896 perduró por 95 años, hasta 1991. Todo lo relacionado con el tema de los nacionales y extranjeros estuvo normado en el Segundo título, denominado De los habitantes: nacionales y extranjeros, el cual contiene 11 artículos. Pertenece a la OIM desde 1957 y legisló desde 1961 sobre los derechos político-electorales de los colombianos en el exterior para elegir al presidente. Ha suscrito múltiples acuerdos regionales e internacionales en relación con los temas de asilo, refugio y respeto a los derechos de los migrantes internacionales y sus familias. Independientemente del contenido del artículo 13, de la Constitución vigente de 1991, es posible destacar los siguientes artículos: Artículo 17, el cual se manifiesta en contra de la esclavitud, la servidumbre y la trata de personas; Artículo 36, en relación con el asilo; Artículo 44, en relación con el trato y respeto de los menores; y el Artículo 100, sobre los extranjeros (Constitución de 1991, p. 32). Son aspectos esenciales a considerar en este documento, ya que le han dado un amplio margen de acción al Presidente Duque en relación con las decisiones que ha tomado en materia de política migratoria para atender los retos del intenso éxodo de migrantes venezolanos a Colombia.

La estructura de la actual política migratoria colombiana está compuesta por la Política Integral Migratoria (PIM), el documento CONPES 3603 de 2009; la Ley 1465 de 2011, que reglamenta el Sistema Nacional de Migraciones; la Ley 1565 de 2012, que reglamenta el Retorno, y el Decreto 1067 de 2015, Decreto Único Reglamentario del Sector Administrativo de Relaciones Exteriores, que reglamenta, entre otros, los flujos migratorios de entrada al país (Ciurlo, 2015).

La Política Integral Migratoria se basa en cinco principios fundamentales para afrontar las dinámicas migratorias y las políticas públicas por implementar:

1. Coherencia y reciprocidad con los demás países;

2. Integralidad y largo plazo para poder afrontar de manera flexible los diferentes escenarios que se presenten y a los que haya que dar respuesta;

3. Concordancia con la política exterior;

4. Plena observancia de las garantías individuales, considerando al migrante como sujeto de derechos y obligaciones según la legislación nacional y el derecho internacional;

5. Y, por último, el principio de focalización, dando prioridad a la atención al extranjero o al colombiano en el exterior en condiciones de mayor vulnerabilidad (Ciurlo, 2015). 
Colombia cuenta con una sólida estructura del Sistema Nacional de Migraciones (SNM). En el marco de las propuestas de la PIM, el Congreso de la República aprobó, mediante la Ley 1465 de 2011, la reforma de la Comisión Intersectorial de Migraciones. Sin eliminar tal entidad, la amplió con la creación del SNM. El nuevo organismo, integrado por una amplia red de instituciones públicas y organizaciones de la sociedad civil, tiene como objetivo apoyar al gobierno y al Ministerio de Relaciones Exteriores en el diseño, aplicación, seguimiento y evaluación de la política migratoria. La idea de fondo fue crear una estructura sólida que reforzara las funciones de la comisión y que también creara un espacio para fomentar la participación de la población migrante en la toma de decisiones relativas al fenómeno migratorio (Ordóñez \& Ramírez Arcos, 2019).

El Estado es consciente de que la población migrante es heterogénea y, además, de que existen diversas categorías; para ello, previó, por un lado, el regreso de personas en condiciones de especial vulnerabilidad, y por otro, el de personas con mayores recursos económicos o con un alto capital humano. En la ley se dispuso el retorno solidario, específicamente para quienes emigraron en calidad de víctimas del conflicto armado; el retorno humanitario, para personas en condiciones de grave precariedad; el retorno laboral y el retorno productivo, para quienes, respectivamente, quieren volver al país para emplear sus capacidades, saberes, oficios y experiencia en el contexto colombiano, o bien para invertir en proyectos productivos vinculados al plan de desarrollo de su departamento y/o municipio de reasentamiento, utilizando recursos propios o las subvenciones de acogida migratoria (Ciurlo, 2015). Se estipula que la política migratoria de Colombia busca proteger a los extranjeros en territorio colombiano y a los colombianos en el exterior, con todas sus categorías y necesidades específicas.

Migración Colombia es un organismo vinculado al Ministerio de Relaciones Exteriores, y es la instancia que se ha encargado del desarrollo de la política migratoria. La entidad, además de las funciones de control y registro de nacionales y extranjeros, está encargada de recolectar y sistematizar la información relativa a los flujos de entrada y salida al país (Ciurlo, 2015). Ahora bien, en 2013, con el Decreto 834, el gobierno aprobó la nueva normativa para la regulación de la inmigración. En la gestión de los flujos de entrada al país, se adoptó un régimen más favorable hacia los trabajadores extranjeros respecto del pasado. Se eliminaron todas las limitaciones contenidas en el Decreto 4000 de 2004 y se designó a Migración Colombia como la entidad que debe, además de ejercer la función del control y registro de los extranjeros, vigilar sus 
actividades, definir las causales de inadmisión y ejecutar las sanciones de deportación y expulsión (Padilla, 2014).

Por otra parte, el Decreto 834 de 2013 simplificó y modernizó el sistema de ingreso, manteniendo el principio de discrecionalidad como elemento central en sus funciones de otorgamiento de visado y de permiso de ingreso y permanencia en el territorio nacional. Además, el decreto redujo los tipos de visa de seis a tres (Negocios, Temporal y Residente) y creó nuevos subtipos para ampliar las diversas actividades que los extranjeros pueden llevar a cabo en Colombia (Ciurlo, 2015).

Adicionalmente, en el gobierno de Iván Duque, el 24 de julio de 2019, el canciller de Colombia, Carlos Holmes Trujillo, radicó en la Secretaría General del Senado de la República el proyecto de ley por medio del cual se establece la política migratoria del Estado colombiano (El Espectador , 2019), la nueva política migratoria está basada en la Política Integral Migratoria (PIM) y la normativa en la que se fundamentó la política migratoria del gobierno de Santos; sin embargo, a la fecha cuenta con una directiva y ocho resoluciones:

Directiva 016 de 2018: Que se encarga de la adopción de documentos y manual de Procesos Gestión Extranjería. Resolución 0285 de 2019: Por la cual se fijan las tarifas por los servicios que presta la Unidad Administrativa Especial Migración Colombia, y el valor de los costos asociados a la expedición de los datos públicos de extranjeros, para la vigencia 2019.

Las Resoluciones 1465, 1567, 2520, 2634 y 3548, todas del año 2019, están dirigidas a emitir, renovar y complementar la estancia regulada de los migrantes venezolanos y solicitantes de asilo, incluidos los ex miembros de las fuerzas armadas y policiales. La Resolución 8470 de 2019 fue la más comentada y valorada por los migrantes venezolanos; por medio de ésta se adopta una medida administrativa, de carácter temporal y excepcional, para incluir de oficio la nota: "Válido para demostrar nacionalidad” en el Registro Civil de Nacimiento de niñas y niños nacidos en Colombia, que se encuentran en riesgo de adquirir la condición de apátridas, hijos de padres venezolanos, que no cumplen con el requisito de domicilio (Migración Colombia , 2019)..$^{2}$

${ }^{2}$ Estas resoluciones están intrínsecamente vinculadas a la vocación nacional expresada en el Artículo 44 constitucional que a la letra dice: Son derechos fundamentales de los niños: la vida, la seguridad física, la salud, y la seguridad social, la alimentación equilibrada, su nombre y nacionalidad, tener una familia y no ser separado de ella... (pp. 13-22). Las resoluciones enfocadas a emitir permisos especiales, ampliarlos y concederles complementariedad tienen relación directa con los padres de los menores para evitar la separación y la condición de apátrida de los menores ya que las oficinas consulares venezolanas no han sido suficientes, ni efectivas. 
Asimismo, el pasado 2 de mayo de 2019, Migración Colombia, por medio de su director general, Christian Krüger Sarmiento, expuso un comunicado donde presenta la cifra, con corte al 31 de marzo, que reconoce la presencia de 1 millón 269000 venezolanos en territorio colombiano. De igual manera, destaca a Santander, La Guajira, Atlántico y Antioquia como las regiones del país en donde más venezolanos se han radicado; esto podría deberse a la cercanía del límite fronterizo con el país vecino o en otras regiones por las oportunidades laborales (Ver Mapa 1).

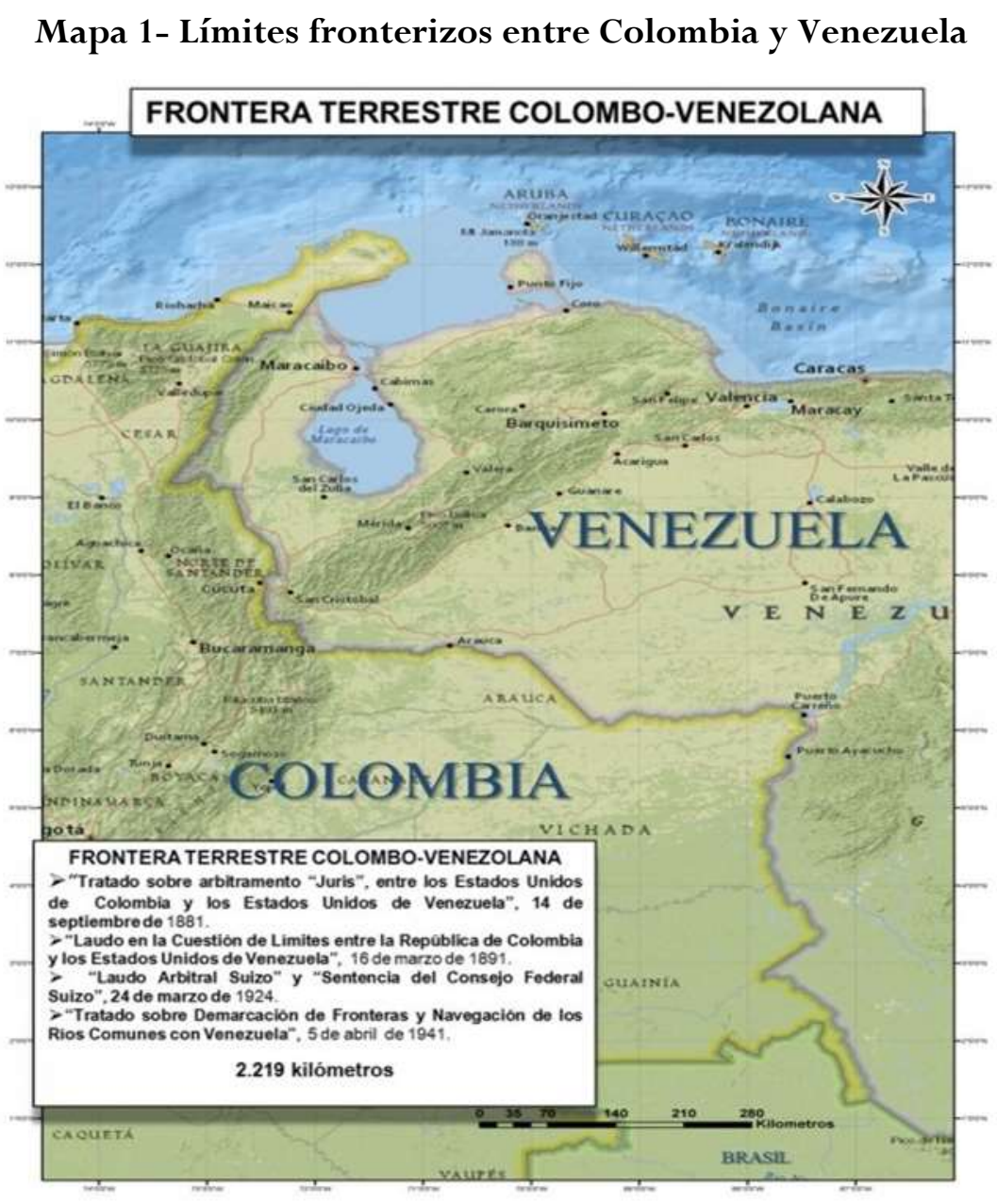

Fuente: Cancillería de Colombia, https://bit.ly/3fs9PEc.

Ahora bien, una de las problemáticas actuales es que el PEP constituye una forma de solidaridad excluyente que legitima temporalmente a ciertos migrantes y deja otros en los márgenes del Estado, donde pueden ser criminalizados por diferentes actores como 
la policía, el ejército, Migración Colombia y otros (Ordóñez \& Ramírez Arcos, 2019). Un ejemplo de esto es la intervención del general Bonett, antiguo comandante general de las fuerzas militares en el marco de un conversatorio sobre la transformación de las Fuerzas Militares colombianas en el posconflicto, en la cual discutió acerca de la “Colombia profunda que no conoce nadie”. En su ponencia identificó a los militares como unos de los pocos testigos del Estado frente a las diferencias del país y en su lista de las principales amenazas a la nación, el general preguntó: “¿Cómo vamos a tocar el problema de Venezuela? [...] Ya el sarampión llegó a Risaralda [...] ¿Será una forma de guerra biológica? [...] Venezuela nos considera un enemigo, y nosotros no, por eso nuestras fronteras están abiertas [...] Entran personas, sin identificación y sin las normas a la entrada que se necesitan” (Ordóñez \& Ramírez Arcos, 2019).

\section{ASPECTOS FUNDAMENTALES EN RELACIÓN CON MIGRANTES VENEZOLANOS}

La llegada de cientos de miles de venezolanos a territorio colombiano en la última década ha dejado de ser una novedad para convertirse en un fenómeno social y económico en Colombia. La compleja situación política por la que está atravesando Venezuela es la principal causa de una migración, en su mayoría está compuesta por personas altamente calificadas y que han ido insertándose exitosamente en diversos sectores productivos (Zuñiga, 2017). Sin embargo, partiendo del informe Radiografía de venezolanos en Colombia, realizado por Migración Colombia del Ministerio de Relaciones Exteriores, el cierre de los 2200 kilómetros de línea limítrofe que comparten Colombia y Venezuela, el 19 de agosto de 2015, provocó la deportación de 2000 colombianos y la entrada a Colombia de 329478 venezolanos (Contreras, 2017).

Una de las estrategias empleadas por el gobierno frente a la crisis migratoria venezolana, fue la implementación del Permiso Especial de Permanencia (PEP), diseñado para migrantes que habían sobre-extendido su permanencia legal en Colombia y entrado al país antes del 28 de julio de 2017, fecha ampliada posteriormente por el Gobierno hasta el 2 de febrero de 2018 (Ordóñez \& Ramírez Arcos, 2019). Dicha estrategia permitió regularizar a muchos migrantes; sin embargo, también excluyó a otra gran cantidad de ellos, que no podían acceder a dicho permiso por la enorme cantidad de obstáculos que se presentaron para ello. Entre los requisitos para obtener el PEP estaban el haber pasado por un puesto de control migratorio oficial y haber sellado el pasaporte, cosa que excluyó a un número significativo de personas por dos razones: la primera es la fluidez de la frontera, la cual es de 2219 kilómetros que históricamente 
ha unido más que separado una amplia área entre los dos países (Ver Mapa 1); la segunda es que, para la mayoría de los migrantes, obtener el pasaporte en Venezuela es casi imposible por las dificultades burocráticas y económicas que representa, puesto que sus instituciones han desarrollado mecanismos formales e informales para entorpecer los flujos migratorios hacia el exterior (Ordóñez \& Ramírez Arcos, 2019). Lo anterior dificulta que la migración venezolana hacia Colombia se dé en forma ordenada y regular, y obliga a muchos migrantes a residir de manera irregular en el país.

Resulta evidente la discriminación hacia los cuerpos de los migrantes venezolanos, no sólo por la salud pública, sino desde el punto de vista laboral, por el trabajo informal que se ven obligados a realizar o los bajos costos de su mano de obra, sino también desde la seguridad. Algunas voces colombianas se han manifestado en referencia a la seguridad al verlos como una posible "amenaza", tanto para la seguridad nacional como para el orden público, y todo esto se constituye en factores clave de una migración que aún no se logra comprender y por ello no se le ha sabido hacer frente.

\section{DIFERENCIAS DEPARTAMENTALES VINCULADAS AL ÉXODO VENEZOLANO}

De acuerdo con los estudios prospectivos publicados por el IMMAP, sobre el éxodo de venezolanos a Colombia: "El patrón de asentamiento de los migrantes y refugiados refleja dos ingredientes: uno espacial y otro económico". El primero se refiere a que a mayor distancia del vecino país, menor número de refugiados y migrantes en el territorio, lo cual explica porque la frontera colombo-venezolana y gran parte de la Región Caribe cuentan con un número considerable de venezolanos.

Figura 2- Población y distribución departamental de los migrantes venezolanos

\begin{tabular}{|c|c|c|c|c|}
\hline Departamentos & $\begin{array}{c}\text { Migrantes } \\
\text { venezolanos }\end{array}$ & $\begin{array}{c}\text { Departamentos } \\
\text { Eje Cafetero }\end{array}$ & Población & $\begin{array}{c}\text { Migrantes } \\
\text { venezolanos }\end{array}$ \\
\hline 1- Bogotá & 262000 & 17 - Risaralda & 839957 & 2785 \\
\hline 2- Barranquilla & 103298 & 21 - Caldas & 923582 & 1578 \\
\hline 3- Cúcuta & 975580 & 22 - Quindío & 509640 & 1275 \\
\hline 4- Medellín & 53082 & & \\
\hline \multicolumn{4}{|l}{ Fuente: Elaboración propia con datos de IMMAP (2019); González Bell (2019). } \\
\hline
\end{tabular}

El segundo se refiere a que las grandes ciudades, al tener economías dinámicas y diversificadas, atraen un alto número de refugiados y migrantes, aun cuando estén muy 
alejadas de la frontera (IMMAP, 2020). La mejor muestra de estas afirmaciones son las estadísticas que se muestran a continuación en la Figura 2: Bogotá, Barranquilla, Cúcuta y Medellín. Por su parte, la región cafetera analizada ha recibido menos del 1\% del total de migrantes venezolanos.

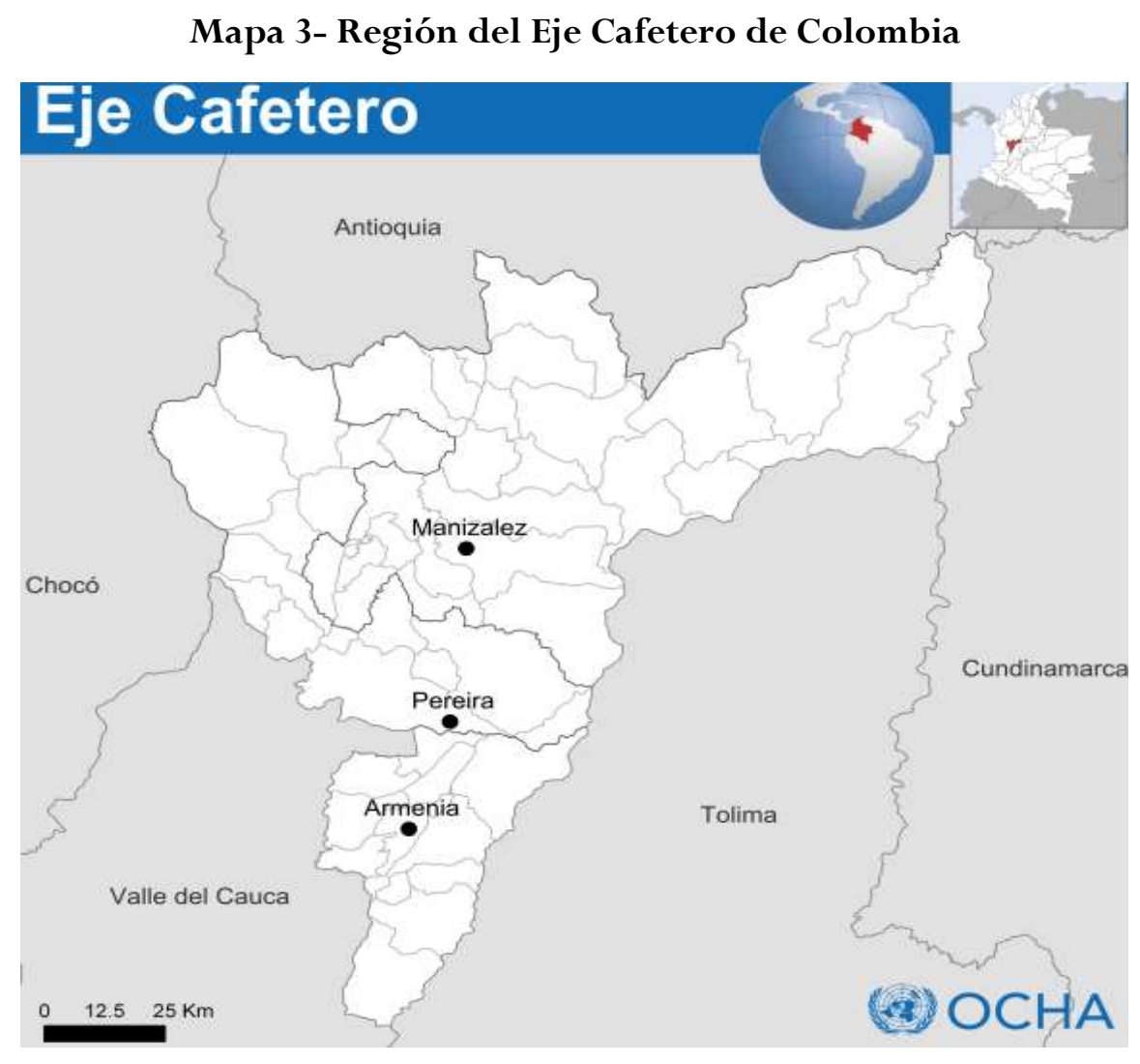

Fuente: Oficina de Naciones Unidas para la Coordinación de Asuntos Humanitarios (OCHA).

La región del Eje Cafetero, conformada por los departamentos de Caldas, Quindío y Risaralda, está situada en la parte central de Colombia, y contiene actualmente 53 municipios; además, de acuerdo con el Departamento Administrativo Nacional de Estadística —DANE- (2012), su territorio ocupa un área total de $13873 \mathrm{~km}^{2}$, representando menos del $2 \%$ de la superficie total del país. A finales del siglo XIX, la región presentó un gran crecimiento demográfico, que según Vallecilla (2005, cit. en Ferney H. Valencia, 2013), fue a causa de procesos de inmigración y altas tasas de natalidad, registrando un crecimiento poblacional mayor que el país desde el año 1870 hasta la segunda mitad del siglo Xx. 
Es necesario decir que el Eje Cafetero cuenta con una historia común, y muy a pesar de la división política de la década de 1960, afirma Gaviria (2020) que la población de los tres departamentos que lo componen: Quindío, Caldas y Risaralda mantienen rasgos sociales y culturales más o menos homogéneos. Manizales y Pereira tienen una especie de historias paralelas y que han mantenido una historia interdependiente en muchos sentidos, tanto a nivel económico y político, como en lo social, lo cultural y lo educativo. Autores como Betancourt (2008), afirman que las ciudades capitales de estos departamentos se relacionan en sus procesos de fundación producto de diversas corrientes migratorias y empresas colonizadoras desde mediados del siglo XIX (Gaviria Rios, 2020). Uno de los rasgos más distintivos de la región es sin duda la producción y comercialización del café. Esto llevó a que Manizales y Pereira fueran conocidas en el contexto nacional como las ciudades "modelo" y "prodigio", respectivamente. De acuerdo con Gaviria (2020): "hacia el año de 1930 la producción cafetera del departamento de Caldas representaba el 29,1\% del total de la producción nacional, cifra que seguiría creciendo durante las décadas de los años 40 y 50 ”.

De acuerdo con información del Instituto Andino de Estudios Sociales (INANDES) sobre el PIB de los departamentos de la región Eje Cafetero, entre 1960 y 1975, ya se observaba una diferencia en la distribución económica. Las actividades comerciales en Risaralda y de alquiler de vivienda en Caldas se consideran variables complementarias al primer sector. Asimismo, el sector secundario, debido al dinamismo de la industria en Risaralda y de la construcción en los tres departamentos, exhibió el $12^{\circ}$ mayor avance en su aporte, que pasó de 15,9\% en 1960 a 23,3\% en 1975 (Ferney H. Valencia Valencia, 2013).

En la década de los noventa se presentaron los mayores movimientos en dichas distribuciones; de esta forma, tanto el sector primario como el secundario fueron perdiendo progresivamente participación por los escasos avances y en algunos años disminuciones en el cultivo de café, en la industria y la construcción, profundizando su detrimento hacia finales de la década, como efecto posiblemente de la crisis económica; es así como, en el año 2000, los sectores primario y secundario llegaron a contribuir con 17,0\% y 20,5\% del PIB regional (Ferney H. Valencia Valencia, 2013).

Es importante destacar el crecimiento poblacional del Eje Cafetero y la férrea lucha política-social de las élites citadinas para encauzar a la sociedad hacia otros tipos de comportamientos y que adoptaran las formas de vida más modernas, de acuerdo con otras grandes ciudades colombianas y latinoamericanas. Actualmente esta región 
representa un 5.2\% de la población total de Colombia, equivalente a 2’536,000 habitantes.

De acuerdo con la Resolución 2079 del 7 de octubre de 2011, en el Ministerio de Cultura se presenta la síntesis del folio presentado ante la 35ª sesión del Comité de Patrimonio Mundial, que se llevó a cabo en la sede de la Unesco en París. La síntesis se respalda en los criterios de integridad y autenticidad para resaltar el valor universal del Paisaje Cultural Cafetero (PCC). Esta resolución propende por desplegar acciones en función de la conservación del PCC y de la delimitación del paisaje a la región denominada Eje Cafetero para poder llevar a cabo las acciones pertinentes al sostenimiento de la declaratoria. Este honor, sólo lo tienen actualmente otros dos paisajes culturales de América Latina: México por el tequila y el sureste de Cuba por sus plantaciones de tabaco. Así el Paisaje Cultural Cafetero es el primero de esta especie en producción, inscrito en la Lista de Patrimonio Mundial (Valencia, 2019).

La apertura económica de 1990 implicó un cambio drástico en la economía colombiana, de allí que el café dejó de ser una de las grandes actividades económicas del país. Este declive en la economía cafetera llevó hacia un desmonte de la caficultura en la región. Las haciendas y parcelas antiguas que se dedicaban al cultivo del café lo reemplazaron por otros cultivos alternativos. Y, como respuesta a la crisis que esto representó para la región cafetera, las fincas que acogían familias numerosas se dedicaron al turismo (Valencia, 2019); esto, sumado a que, para 2015, ya otras regiones del país habían superado los departamentos del Eje Cafetero en cuanto a la producción del café: Huila, Antioquia y Cauca ocupan los tres primeros lugares, tan solo hasta el cuarto lugar aparece Caldas, mientras que Pereira se ubica en el séptimo puesto y el Quindío en el puesto número 11 (Martínez, 2017, cit. en Valencia, 2019).

En relación con el éxodo venezolano, esta región es una de las menos concurridas ya que, de acuerdo con la Figura 2, las estadísticas muestran menos del 1\% de los migrantes. El departamento de Caldas ha presentado un incremento del 113\% de refugiados y migrantes venezolanos desde junio del 2019, es el departamento del Eje Cafetero con mayor crecimiento. Armenia con un $78,4 \%$ es la ciudad con mayor concentración de refugiados y migrantes venezolanos en Quindío, seguido de Pereira (Risaralda) con 67,3\% y Manizales (Caldas) con 64\%. El 69,33\% de refugiados y migrantes venezolanos en el Eje Cafetero se concentra en las tres capitales. Si la zona del Eje Cafetero fuese un departamento, sería el $13^{\circ}$ con el mayor número de población refugiada y migrante (OIM, 2019).

Clivajes. Revista de Ciencias Sociales (ISSN: 2395-9495), Año VIII, Núm. 15, enero-junio, 2021 Instituto de Investigaciones Histórico-Sociales, Universidad Veracruzana, México 


\section{RESULTADOS DE ENTREVISTAS A MIGRANTES VENEZOLANOS}

En un balance concreto de percepciones, logramos establecer contacto y realizar entrevistas semi-estructuradas, que constan de 12 preguntas, a 56 personas: 30 venezolanas y 26 colombianas.

\begin{tabular}{|c|c|}
\hline Preguntas para migrantes venezolanos/as & Preguntas para colombianos/as \\
\hline $\begin{array}{l}\text { 1. ¿Cuánto tiempo tiene viviendo en } \\
\text { Colombia/Manizales? }\end{array}$ & $\begin{array}{l}\text { 1. ¿Reconoce a los migrantes venezolanos que } \\
\text { están en la ciudad? }\end{array}$ \\
\hline 2. ¿Con quién vive? & $\begin{array}{l}\text { 2. ¿Ha tenido algún tipo de conversación o } \\
\text { relación con algún migrante venezolano/a? }\end{array}$ \\
\hline 3. ¿Cón & $\begin{array}{l}\text { 3. ¿Ha leído alguna noticia local o nacional } \\
\text { sobre los migrantes venezolanos? }\end{array}$ \\
\hline $\begin{array}{l}\text { 4. ¿Cuál es su formación o experiencia laboral } \\
\text { en Venezuela? }\end{array}$ & $\begin{array}{l}\text { 4. ¿Conoce usted alguna ley o decreto del } \\
\text { gobierno nacional en relación a los } \\
\text { migrantes? }\end{array}$ \\
\hline $\begin{array}{l}\text { otivos por los que emigró o } \\
\text { dela? }\end{array}$ & $\begin{array}{l}\text { 5. ¿En su familia hay migrantes fuera de } \\
\text { Colombia o desplazados dentro? }\end{array}$ \\
\hline $\begin{array}{l}\text { 6. ¿Cuáles son sus actividades laborales en } \\
\text { Manizales? }\end{array}$ & $\begin{array}{l}\text { 6. ¿Ha visto usted los noticieros locales o } \\
\text { nacionales que presentan a los grupos de } \\
\text { migrantes venezolanos caminando por las } \\
\text { carreteras y calles de Colombia? }\end{array}$ \\
\hline 7. ¿Viv & $\begin{array}{l}\text { 7. ¿Ha leído en los } \\
\text { celular alguna } \mathrm{n} \\
\text { venezolanos en su }\end{array}$ \\
\hline 8. ¿Có & $\begin{array}{l}\text { 8. ¿Conoce o ha escuchado alguna declaración } \\
\text { de las autoridades municipales o } \\
\text { departamentales sobre la llegada de los } \\
\text { migrantes venezolanos a la ciudad? }\end{array}$ \\
\hline $\begin{array}{l}\text { 9. ¿Cómo le ha tratado la gente de Manizales? } \\
\text { ¿Su empleador, su rentero? }\end{array}$ & $\begin{array}{l}\text { 9. ¿Ha comprado dulces o comida, empleado o } \\
\text { rentado un espacio de vivienda a los } \\
\text { migrantes venezolanos? }\end{array}$ \\
\hline $\begin{array}{l}\text { 10. ¿Ha utilizado los servicios de salud? ¿cómo } \\
\text { los califica? }\end{array}$ & $\begin{array}{l}\text { 10. ¿Qué le gustaría saber sobre la llegada de } \\
\text { migrantes venezolanos a la ciudad? }\end{array}$ \\
\hline $\begin{array}{l}\text { 11. ¿Tiene planes, o piensa regresar a Venezuela } \\
\text { en un futuro? }\end{array}$ & $\begin{array}{l}\text { 11. Para empleadores: En esta ciudad hay } \\
\text { desempleo, ¿Por qué contrataría a un } \\
\text { migrante venezolano? }\end{array}$ \\
\hline $\begin{array}{l}\text { 12. ¿Ha tenido algún trato con funcionarios de } \\
\text { gobierno, policía u otra dependencia } \\
\text { Colombiana? }\end{array}$ & $\begin{array}{l}\text { 12. Para rendatarios de vivienda: ¿Cómo ha sido } \\
\text { la respuesta en pagos, comportamiento, y } \\
\text { cuidado de la vivienda de los migrantes } \\
\text { venezolanos? }\end{array}$ \\
\hline
\end{tabular}

Tabla de preguntas elaborada por los autores, con la ayuda de colaboradores. Universidad Autónoma de Manizales, agosto 2019. 
Entrevistas a migrantes venezolanos radicados en Manizales y Pereira, en su mayoría vendedores ambulantes de dulces y comida o dedicados a oficios varios en mercados, salones de belleza y expendios de alimentos.

Hombres, 18; mujeres, 12

Rango de edades: Menores de 20 años, 4; De entre 21 y 30 años, 19; De entre 31 y 40 años, 4; mayores de 41 años, 3.

Causas de la migración: desempleo, inflación, falta de oportunidades, persecución policial

Tipos de vivienda; cuartos con el mínimo de servicios, compartidos con dos o más personas

Actividades: mercados, salón de belleza, vendedores ambulantes (dulces y alimentos).

De la ciudad opinan que es más bonita, pintoresca, llueve mucho, muy buen servicio de transporte público.

De la gente de Manizales: es muy amable y educada, nos compran dulces y arepas en la calle. Los dueños de las viviendas te rentan si traes plata, y te vigilan para que no tengas a más familia que la que registras. Si no tienes permiso válido no te dan trabajo. Varios de nosotros no tenemos permiso válido.

De los servicios de salud: un 40\% los han utilizado y cuatro opiniones distintas entre muy bueno, bueno, malo y hasta peor que en Venezuela.

Los servicios del gobierno y trato con la policía: preferimos esperar a los cambios en la ley de migración para renovar el permiso, tratamos de pasar desapercibidos cuando pasa la policía. Un 50\% de los/las entrevistados no tiene o su permiso temporal estaba vencido.

La gran ventaja de este proyecto es que contamos con dos estudiantes jóvenes, intrépidos, y con el compromiso de contribuir al proyecto de investigación universitario "exploratorio" sobre los migrantes venezolanos en sus ciudades. Fue a través del ojo clínico del investigador-guía que se nos facilitó localizar a una primera pareja de vendedores ambulantes de dulces con quienes entablamos una conversación informal. En el transcurso de la compra de dulces, utilizamos un billete mayor al precio de los dulces con el objetivo de observar y preguntar cómo habían estado las ventas del día. Entre los dos vendedores completaron el cambio de un billete de diez pesos 
colombianos y, mirándose fijamente entre ellos, la mujer respondió: “mira, pues te completamos el cambio, señal que ya hemos vendido algo este día”. "Hay días mejores", añadió el hombre. Regresamos al día siguiente y allí estaban los vendedores de dulces, en el mismo espacio del día anterior. Volvimos a comprar de los mismos dulces y la mujer nos reconoció: "ustedes compraron ayer, ¿es verdad?" Respondimos ambos con la cabeza aprobando la afirmación de Katerine. Así empezó el proceso de ganar confianza con la primera pareja de venezolanos en la ciudad de Manizales: José Luis y Katerine.

En el segundo encuentro les platicamos que somos un grupo de profesor y estudiantes en la Universidad Autónoma de Manizales (UAM) y de México, de la Universidad Autónoma de Nayarit, y que estábamos buscando migrantes venezolanos para platicar con ellos con el objetivo de corresponder a un proyecto universitario. Ellos accedieron y lo primero que hicieron fue presentarnos a su bebe, de 8 meses. Después nos preguntaron por México: “Cómo está esa ruta para llegar a los EE.UU.? ¿Y el tequila y los mariachis?” Nos compartieron sus edades, su lugar de procedencia y las actividades que realizaban en Venezuela antes de emigrar. Ante la pregunta de las causas que les motivaron a emigrar, José Luis respondió: “se acabó el trabajo en mi empresa, ya nadie enviaba nada. Y la familia con la que trabaja mi esposa también se fue de Venezuela, así que los dos nos quedamos sin empleo en seis meses. Los ahorros eran pocos y antes que se acabaran decidimos venirnos a Colombia, a Bogotá. Pero allá hay muchos venezolanos y mucha gente colombiana sin trabajo, así que un amigo me platicó de Manizales y nos venimos para acá, para que naciera David, hace 8 meses".

Otra de las preguntas que hicimos a todos los entrevistados fue: ¿Cómo se han sentido en Manizales y cómo los trata la gente? "Con frío y llueve mucho”, respondió Jacqueline entre sonrisas. "La mayoría de la gente aquí es amable, es muy educada y nos han ofrecido comida”; “algunos nos traen ropa para ella y para el bebé”, agregó José Luis. "En el salón de belleza hay clientes de todo; incluso hay clientas que no quieren que yo las atienda. Otras son muy amables y no sé si sean morbosas o realmente quieren saber que está pasando en mi país”, completó la respuesta Jacqueline, quien trabaja en un salón de belleza tres días de la semana, o "cuando se le pasa el camión de las fresas a José Luis”. Cada respuesta estaba acompañada de miradas entre la pareja. Parecía que todavía no lográbamos del todo entablar confianza. “¿Cómo está eso del camión de las fresas, a qué se refiere?" José Luis, un poco desconcertado retomó la palabra: "ella se refiere a mi actividad principal de las mañanas, que es vender fresas. Y hay veces que no llego a tiempo al crucero donde pasa el camión, cerca de las cuatro de 
la mañana, y me quedó sin la caja de fresas. Esas mañanas cuido al niño y ella se va al salón a trabajar. Por la tarde es el segundo trabajo, que es la venta de dulces”.

Los encuentros con José Luis y Jacqueline nos permitieron conocer a otros migrantes venezolanos. Ellos nos indicaron los lugares en donde trabajan y en la misma vivienda nos recomendaron a otra pareja de venezolanos conocidos. Así es que conocimos a Tamara, de 21 años y estilista de profesión. Tamara opina que las personas de Manizales son amables; tanto los clientes del lugar como el dueño del salón de belleza. Tamara también mencionó que ha utilizado los servicios médicos de Manizales y expresó que le prestaron la debida atención. Tamara respondió que decidió venir a Colombia con otros tres amigos, ya que se encontraban en Venezuela sin empleo y sin esperanzas de encontrar uno en el corto plazo. A través de José Luis y Jacqueline, también conocimos al responsable de la vivienda que les rentaba y al núcleo familiar de Cristhian Torres.

Cristhian Torres Mendoza, entrevistado en octubre 5 de 2019, es vendedor ambulante en el sector de Palermo; de 19 años, procedente de Puerto Cabello Venezuela, lleva cinco meses en el país, de los cuales tres ha estado en Manizales. Se encuentra en la ciudad actualmente con sus dos hermanos menores, su madre y una tía, todos son vendedores ambulantes en diferentes partes de la ciudad. En los primeros días en la ciudad alquilaban dos habitaciones en el sector de la Galería, pero actualmente alquilaron una habitación con tres camas, ubicada en el centro de la ciudad en donde residen él y sus cuatro familiares. El día de Christian inicia a las ocho de la mañana con su visita a un punto de venta de dulces al por mayor (bodega), ubicado a tres cuadras de su actual residencia. La Avenida Santander es su espacio de venta de dulces, hasta las nueve de la noche, hora en la que, dependiendo de sus ventas diarias, decide si paga trasporte público hasta su lugar de residencia o si de nuevo regresa caminando. La familia hace cuentas durante la noche y Cristhian vuelve a la bodega cada mañana a surtir los dulces a precio de mayoreo.

La población receptora de ciudadanos venezolanos en Manizales y Pereira ha sido participe del éxodo de venezolanos no sólo en estas dos ciudades donde se puede evidenciar este fenómeno social, sino también en el resto de Colombia, como lo pueden ver en medios de comunicación nacionales. Cada una de las ciudades recibe en pequeña o gran medida a migrantes venezolanos que vienen al país en busca de mejores oportunidades para ellos y para sus familias. En el Eje Cafetero, como se evidenció anteriormente, no es muy grande la cantidad de migrantes que reciben ciudades como Pereira, Manizales y Armenia, puede ser por esto que la respuesta de los colombianos 
en estas tres ciudades aún no sea tan negativa como en otras urbes, como Bogotá, Barranquilla o Medellín, en donde la imagen desfavorable de los venezolanos aumenta cada vez más.

Sin embargo, en las entrevistas realizadas a manizaleños, algunos manifestaron críticas al gobierno central por la adopción de resoluciones y decretos a favor de los migrantes venezolanos, cuando los mismos colombianos están en condiciones de pobreza, desempleados o carentes de servicios sociales, por la alta tasa de informalidad. Coinciden estos razonamientos con las declaraciones que hace el experto en temas laborales, Carlos Cardona, quien afirma que el desempleo alcanzó un 11.95\% en la región del Eje Cafetero durante el año 2019. Y, además señaló que la excelencia universitaria está muy por encima de la creación de empleos formales, por lo que se observa una emigración de jóvenes egresados de las universidades hacia otras ciudades colombianas (González Bell, 2019).

Las opiniones acerca de las decisiones institucionales para administrar los flujos migratorios se encuentran divididas. Es una realidad que las autoridades locales carecen de un plan de acción relacionado con los nuevos migrantes. En Pereira existe una percepción, mayor que en Manizales, referente a que los migrantes venezolanos están encauzados a cometer delitos en agravio de la sociedad receptora, como robo en vivienda, autos y calle. Otro aspecto que se identificó fue la falta de interés y de estudiosos del tema migratorio en la región, y, por lo tanto, inexistencia de documentos de divulgación e investigación científica al respecto en cinco instituciones educativas de tres departamentos de la región de interacción durante la estancia académica (Armenia incluida).

Los migrantes venezolanos expresan preocupación por la situación política de su país. Ellos describen que ha afectado los niveles de desempleo/ingresos y bienestar de la mayoría de la población, y los ha motivado a emigrar a países vecinos como solución para la situación política, económica y social a la que se enfrentaban ellos y sus familias en Venezuela.

Un aspecto que cabe destacar es que de los 30 venezolanos a los cuales se les realizó la encuesta semi-estructurada, 14 aseguraban contar con estudios técnicos que no pueden ejercer en Colombia, debido a la falta de documentación, a que la demanda de trabajos en otros oficios menos calificados es mayor, y también, debido a su condición legal y económica en el país, deben dedicarse a los trabajos informales que les resulten.

Clivajes. Revista de Ciencias Sociales (ISSN: 2395-9495), Año VIII, Núm. 15, enero-junio, 2021 Instituto de Investigaciones Histórico-Sociales, Universidad Veracruzana, México 


\section{CONCLUSIONES}

Concluimos que el tema de la migración de venezolanos en Colombia es el más latente en los tres años más recientes (2017-2020) entre la sociedad colombiana, políticos, representantes extranjeros y funcionarios de los organismos internacionales que trabajan en conjunto con las instancias colombianas. La intensidad de las relaciones transfronterizas de Venezuela con Colombia se enmarca en la teoría de la interdependencia compleja que aportan Kehoane y Nye. El de las migraciones internacionales se reconoce como el tema central de la agenda binacional y con otros países de la región de América Latina. Queda clara la inclusión de conceptos sobre las dimensiones migratorias que se identifican en la normativa y coinciden en los antecedentes migratorios históricos de Colombia. Coincidimos con los medios de comunicación y las expresiones de nuestros entrevistados: "El gobierno colombiano ha publicado resoluciones, implementado decretos y emitido discursos, y por supuesto que ha implementado algunas estrategias de atención a los migrantes. Sin embargo, también coincidimos con las declaraciones de los funcionarios gubernamentales de todos los niveles: "El éxodo de venezolanos es tan superior a todo lo imaginado que no existe, ni existirá capacidad en Colombia para satisfacer todas sus necesidades”. Por lo tanto, queda de manifiesto que el gobierno de Colombia está haciendo su parte en la actualización de sus leyes y reglamentos relacionados con la gestión de las migraciones y la gestión de la frontera; eso lo coloca en un primerísimo lugar en lo referente a la gestión y las prácticas migratorias en América Latina.

Una parte de la sociedad colombiana mantiene la conciencia histórica activa y reconoce el papel que jugó Venezuela recibiendo a miles de colombianos en su territorio por décadas; sobre todo, reconoce la intensa movilidad, los desplazamientos humanos por la violencia y la extensa emigración de colombianos hacia el exterior del país. La mayoría de la población colombiana está consciente del conflicto venezolano y se encuentra en un proceso de entendimiento y asimilación de las nuevas disposiciones y posturas del su gobierno para administrar la llegada masiva de migrantes y ofrecer mejores condiciones. Existen opiniones encontradas en relación con el Gobierno central de Colombia. Se le acusa de limitaciones en sus estrategias para ayudar a los venezolanos inmigrantes, ya que son distintos tipos, rutas y espacios de asentamiento y no se vislumbran vías claras de cooperación y colaboración con los gobiernos locales.

Se emiten discursos con estadísticas aproximadas de las personas que han ingresado al país, pues sólo se tiene control de aquellas personas que ingresan por los 
puestos autorizados, dejando de lado a quienes ingresan de manera regular. Las cifras son aproximadas y este desconocimiento provoca distintos niveles de percepción de la población colombiana, de ciertos departamentos, por lo que permanecen actitudes de discriminación (Zuñiga, 2017). El descontrol informativo es lo que ha ocasionado que una parte de la población colombiana se sienta incómoda con el proceso de migración, todo debido a la falta de preparación de los colombianos para acoger a los migrantes, y, a la vez, a la falta de políticas verdaderamente eficientes por parte del Estado colombiano.

Ahora bien, es importante resaltar, además de las relaciones inter-Estatales, cómo se dan los lazos de interdependencia — simétrica — en la realidad actual de los migrantes venezolanos. La muestra exploratoria que realizamos con 30 migrantes expresó que muchos, a pesar de ser bien recibidos en la ciudad de Manizales, han sufrido de acoso, xenofobia en la ciudad cercana de Pereira, o padecen de necesidades materiales, abuso de autoridad y carencia de servicios (Gramsci, 1975) sociales. Desde nuestra perspectiva, estos aspectos de percepción negativos han sido expresados como puntos que justifican la necesidad del Estado colombiano de registrar biométricamente a los migrantes.

Otro asunto que se debe valorar y no perder de vista, es la intención gubernamental de elevar la percepción y el reconocimiento internacional del presidente Duque ante los organismos internacionales y representes de la Unión Europea y Estados Unidos. Los factores que motivaron el enuncio presidencial de este ambicioso programa de regularización migratoria para todos los venezolanos que residen en Colombia merecen seguimiento como parte de los nuevos procesos que emergen como consecuencia de las migraciones internacionales. Es entonces que esto deja tres grandes interrogantes.

En primer lugar, la manera en la que se estaba haciendo frente al fenómeno de la migración venezolana en Colombia no cumplía con los marcos de un proceso integral, puesto que se perdían de vista muchas de las necesidades básicas de los migrantes y se exhibían los abusos de autoridad, falsificación de documentos y corrupción para lograr el acceso a los servicios sociales básicos.

En segundo lugar, el hecho de que se necesitara diseñar una política integral de concientización sobre la realidad de los migrantes y sus derechos, para disminuir los casos de acoso y hacer frente de manera radical a la xenofobia, que es además injustificada puesto que Colombia registra una intensa historia de sus propias 
migraciones internas/externas similares a las de México. Por si esto no fuera suficiente, Colombia tiene reconocida una larga trayectoria de entendimiento y gestión de las migraciones como un derecho de todos los individuos; por ello, dichas campañas de concientización deben estar incluidas en un plan integral de tratamiento al migrante. Parece que el anuncio estratégico ante representantes internacionales del presidente Duque ha tenido sus efectos positivos en términos de percepción mediática. Estaremos atentos al proceso legislativo y la ejecución del plan.

Por último, la conclusión que se puede extraer de la muestra exploratoria es que las experiencias de los migrantes venezolanos en la ciudad de Manizales han sido positivas, y que su percepción de la ciudad y de sus habitantes es favorable, lo cual demuestra que es un ambiente saludable para el acogimiento de las poblaciones migrantes. Sin embargo, las experiencias en la ciudad de Pereira registran percepciones mixtas con un alto contenido de xenofobia y violencia.

\section{REFERENCIAS}

ACNUR . (2018). ACNUR Colombia y el Registro de venezolanos. ACNUR. ACNUR. (2014). Texto de la Convención de Apátridas de 1954 (p. 3). ACNUR.

BBC. (2019). Crisis de Venezuela: El éxodo de los venezolanos es el mayor de Latinoamérica en los últimos 50 años. BBC News.

Borja TAmayo, A. (2020). Roberth O. Keohane: Interdependencia, Cooperación e Instituciones internacionales. En Velázquez Flores, R., Schiavon, J. A., Morales RamíreZ, D. (Eds.), Los Clásicos de las relaciones internacionales. Ideas y conceptos para la construcción clásica de la disciplina. AMEI-CIDE-UABC.

Cancilleria COlOmbiana. (05 de Agosto de 2019). Declaración sobre resolución que otroga ciudadania colombiana a hijos de venezolanos. Obtenido de Cancilleria : https: / / bit.ly/3KcHakn.

Ciurlo, A. (2015). Nueva política migratoria colombiana: El actual enfoque de inmigración y emigración. Revista Internacional de Cooperación y Desarrollo, 205242.

COMisión Mundial. (2005 ). Las migraciones en Ginebra Suiza: SRO-Kundig.

Contreras, V. A. (2017). Desafíos de la institucionalidad colombiana: caso migración transfronteriza de venezolanos a San José de Cúcuta en el periodo 2015 a julio 
de 2017. Pontificia Universidad Javeriana, Facultad de Ciencias Políticias y Relaciones Internacionales, 1 - 73.

EL EsPeCtAdor . (24 de Julio de 2019). Gobierno radica proyecto de ley para establecer una política migratoria. El Espectador .

Valencia Valencia, F. H., Cortázar Gómez, D. M., López Soto, A. M. (2013). Composición de la Economía de la Región del Eje Cafetero de Colombia. Ensayos Sobre Economía Regional Banco de la República, 1-55.

Gaviria Rios, M. A. (2020). Caracterización funcional de la RAP Eje Cafetero, Colombia. Revista Brasileira de Region, 12.

Gaviria Rios, M. A. (2020A). Territorialidades en El Eje Cafetero Colombia. Recuperado de https: / / bit.ly/320qw6z.

GonzÁlez Bell, J. (15 de julio, 2019) El Eje Cafetero participa con 4\% en el PIB nacional y representa $4.7 \%$ de la población. La República. Recuperado de https: / / bit.ly/3FulOLR.

Gramsci, A. (1975). Cuadernos de la Carcel. Giulio Einaudi Editore S.p.A.

Galeano David, H. ET AL. (2019). Evolución de la política exterio de Colombia en el período 2002-2018. OASIS, 57-79.

IMMAP, Refugiados y migrantes venezolanos con vocación de permanencia en Colombia. Recuperado de https://bit.ly/3FxP0Sa.

Keohane y NyE (2008). Transnational Relations and World Politics. Center of international afairs Harvard University.

Migración Colombia. (2019). Cifra de venezolanos en Colombia. Migracion Colombia Informe Oficial.

Migración Colombia (12 de Octubre de 2019). Migración Colombia . Recuperado de https: / / bit.ly/3I4lFk2.

Migración COlOmbia y dANE (2017). Extranjeros en Colombia: Aproximación migratoria a las trayectorias en Colombia 2005-2016. Recuperado de https: / / bit.ly/33j7rNu.

OIM. (s/f). Términos fundamentales de la migración. Recuperado de https: / / bit.ly/3Kau33p.

OIM. (2018). Informe sobre las migraciones en el mundo. OIM.

OIM. (2019). Venezuela y Colombia: unidos por su gente. OIM.

OIM. (2019). Informe sobre las migraciones. OIM.

Ordóñez, J. T., \& RAmírez Arcos, H. E. (2019). (Des)orden nacional: la construcción de la migración venezolana como una amenzasa de salud $\mathrm{y}$ seguridad pública en Colombia. Revista Ciencias de la Salud, 48-68.

Clivajes. Revista de Ciencias Sociales (ISSN: 2395-9495), Año VIII, Núm. 15, enero-junio, 2021 Instituto de Investigaciones Histórico-Sociales, Universidad Veracruzana, México 
Padilla, C. (2014). La política migratoria colombiana en el periodo de 2002-2010. El Programa Colombia nos une (CNU) (pp.181-182). Centro de Estudios Avanzados.

Constitución Politica de Colombia (1991). Articulo 13.

Redacción Internacional. (1 de Agosto de 2019). Número de venezolanos en Colombia es mayor a la población de Barranquilla. El Espectador .

Ribas, C. V. (09 de 2018). Cordinadora Regional de Investigaciones Economicas y Sociales. cries.org. Recuperado de https://bit.ly/34TLjtx

Tokatlian, J. G., Romero, C. A., Hirst, M. y Luján, C. (Mayo, 2019). Venezuela: paz y seguridad: Hacia una solución política pacífica. Recuperado de https://bit.ly/3rcZPUI.

VAlenCia, L. M. (2019). Cultura y valores asociados al paisaje cultural cafetero. Repositorio Universidad Tecnológica de Pereira, 1- 61.

ZuÑIGA, F. A. (2017). El impacto social de los inmigrantes venezolanos y las incidencias en Colombia. Universidad Militar Nueva Granada, 1 - 7. 